\title{
Increased PCSK9 Cerebrospinal Fluid Concentrations in Alzheimer's Disease
}

\author{
Francesca Zimetti ${ }^{\mathrm{a}}$, Paolo Caffarra ${ }^{\mathrm{b}}$, Nicoletta Ronda ${ }^{\mathrm{a}}$, Elda Favari ${ }^{\mathrm{a}}$, Maria Pia Adorni ${ }^{\mathrm{a}}$, \\ Ilaria Zanotti ${ }^{\mathrm{a}}$, Franco Bernini ${ }^{\mathrm{a}, *}$, Federica Barocco ${ }^{\mathrm{b}}$, Marco Spallazzi ${ }^{\mathrm{b}}$, Daniela Galimbertic \\ Chiara Ricci $^{\mathrm{d}}$, Massimiliano Ruscica ${ }^{\mathrm{d}}$, Alberto Corsini ${ }^{\mathrm{d}, \mathrm{e}}$ and Nicola Ferri ${ }^{\mathrm{f}}$ \\ ${ }^{a}$ Department of Pharmacy, University of Parma, Parma, Italy \\ ${ }^{\mathrm{b}}$ Department of Neurosciences, University of Parma, Parma, Italy \\ ${ }^{\mathrm{c}}$ Neurology Unit, Department of Pathophysiology and Transplantation, University of Milano, \\ Fondazione Cà Granda, IRCCS Ospedale Policlinico, Milano, Italy \\ ${ }^{\mathrm{d}}$ Dipartimento di Scienze Farmacologiche e Biomolecolari, Università degli Studi di Milano, Milano, Italy \\ e Multimedica IRCCS, Milano, Italy \\ ${ }^{\mathrm{f}}$ Dipartimento di Scienze del Farmaco, Università degli Studi di Padova, Padova, Italy
}

\begin{abstract}
.
Background: Alzheimer's disease (AD) has been associated with dysregulation of brain cholesterol trafficking and abnormal production of apolipoprotein E isoform 4 (apoE4). Proprotein convertase subtilisin/kexin type 9 (PCSK9) is a protein present in serum and cerebrospinal fluid (CSF) degrading the low-density lipoprotein receptor (LDLr) and other apoE-binding receptors involved in neuron cholesterol uptake. The role of PCSK9 in AD is controversial.

Objective: We compared PCSK9 levels in CSF of AD patients and non-AD controls and looked at correlations with CSF total apoE and apoE4.

Methods: CSF from $\mathrm{AD}(n=30)$ and from age and sex-matched non-AD patients $(n=30)$ was collected by lumbar puncture for routine diagnosis. CSF PCSK9, total apoE, and apoE4 levels were measured by ELISA. AD patients showed the typical CSF neurobiomarker pattern (decreased $A \beta_{42}$ and increased tau and phospho-tau) and impaired cognitive performances, as indicated by the scores of the Mini-Mental State Examination test.

Results: PCSK9 levels in CSF were higher in AD than in non-AD subjects $(+1.45$ fold; $p=0.0049)$. CSF total apoE concentrations did not differ between the two groups, while apoE4 levels were higher in AD subjects ( +3.34 fold; $p=0.0068)$. Considering all samples, a significant positive correlation was found between PCSK9 and apoE4 $(\mathrm{r}=0.4409 ; p=0.0006)$. PCSK9 levels were higher in APOE $\varepsilon 4$ carriers, reaching statistical significance in the AD group ( +1.45 fold; $p=0.0454)$.

Conclusion: These results report for the first time an alteration of CSF PCSK9 levels in AD and suggest a pathophysiological link between PCSK9, apoE4, and AD.
\end{abstract}

Keywords: Alzheimer's disease, apolipoprotein E4, cerebrospinal fluid, cholesterol, human, proprotein convertase subtilisin kexin 9

\section{INTRODUCTION}

Alterations of cholesterol homeostasis in the central nervous system (CNS) have been associated

\footnotetext{
${ }^{*}$ Correspondence to: Professor Franco Bernini, Department of Pharmacy, University of Parma, Parco Area delle Scienze 27/A, 43124 Parma, Italy. Tel.: +39 0521 905039; Fax: +39 0521 905040; E-mail: fbernini@unipr.it.
}

with various neurodegenerative disorders, including Alzheimer's disease (AD).

The relationship between lipid homeostasis derangement and $\mathrm{AD}$, in particular, is suggested by growing evidence. For example, dyslipidemia, a common condition leading to cardiovascular diseases, is also a risk factor for $\mathrm{AD}$ onset [1]; in addition, genomic-wide association studies have identified several loci involved in lipid metabolism among AD 
susceptible genes [2]. Apolipoprotein E4 (apoE4), a molecule that strongly associates with a higher $\mathrm{AD}$ risk, has a reduced capacity to be lipidated and to modulate cell cholesterol trafficking compared to other apoE isoforms, both at periphery and in CNS $[3,4]$. Cell cholesterol metabolism at central level involves the production of apoE-containing high-density lipoprotein (HDL)-like particles that are transported in cerebrospinal fluid (CSF) and that redistribute cholesterol to neurons. This function ensures synaptogenesis and physiological functions maintenance. Disturbances of such cholesterol flux may play an important role in neurodegenerative disorders [5].

Proprotein convertase subtilisin/kexin type 9 (PCSK9) is a serine protease firstly described to target hepatic low-density lipoprotein receptor (LDLr) and to mediate its degradation [6]. Gain-of-function PCSK9 mutations lead to increased levels of serum LDL cholesterol and loss-of-function mutations prevent the degradation of the hepatic LDL, resulting in a higher clearance of plasma LDL-cholesterol [7]. However, PCSK9 has several extrahepatic effects [8]. PCSK9 was firstly identified in the brain [9] and is detectable in the CSF of healthy subjects without the typical diurnal pattern of plasma PCSK9, indicating a different regulation in the two body compartments [10]. In neurons, PCSK9 has been shown to degrade LDLr as well as other apoE-binding receptors such as the very low-density lipoprotein receptor (VLDLr), the LDL receptor-related protein 1 (LRP1) and the apolipoprotein E receptor 2 (apoER2) [11, 12]; these proteins are involved in the internalization of the cholesterol transported within CSF by HDL-like particles [5, 12]. Thus, PCSK9 modified activity might in principle be involved in the derangement of brain cholesterol trafficking and lipoprotein homeostasis and in $\mathrm{AD}$ pathogenesis. In this work, we measured PCSK9 in CSF of AD patients to establish whether PCSK9 levels alterations occur in $\mathrm{AD}$ and looked for a correlation between PCSK9 values and CSF total apoE and apoE4.

\section{MATERIALS AND METHODS}

\section{Subjects and methods}

CSF samples from AD patients $(n=30)$ and ageand sex-matched non-AD controls $(n=30)$ were collected at the Neurology Units of Parma and Milano after written informed consent obtained using a form approved by the local Ethics Committee. The study was performed in accordance with the ethical principles set in the Declaration of Helsinki of 1975. CSF was collected between 8 and 10 a.m. after one night fasting by lumbar puncture for routine clinical diagnosis and immediately stored at $-80^{\circ} \mathrm{C}$. None of the samples presented alterations at the physicochemical evaluation.

The diagnosis of $\mathrm{AD}$ was made according to NINCDS-ADRDA [13] and subsequent research criteria [14]. The CSF neurobiomarker profile (amyloid- $\beta(\mathrm{A} \beta)_{42}$, tau, and phospho-tau levels) was evaluated by ELISA (Fujirebio, Ghent, Belgium). Global cognitive performance was assessed with the Mini-Mental State Examination (MMSE) test. All clinical diagnoses of non-AD control subjects were reported in Table 1. This group included subjects that experienced cognitive symptoms $(n=6)$ [psychiatric disorders $(n=4)$, alcohol abuse $(n=1)$, and dural fistula $(n=1)$ ], but in which clinical examination revealed disorders not related to $\mathrm{AD}$, as indicated by the values of the neurochemical markers reported in Table 2. The other non-AD diagnoses $(n=24)$ include neurological disorders, hydrocephalus, not confirmed CNS diseases, and neuropathies (Table 1).

Table 1

Clinical diagnosis of non-AD control subjects

\begin{tabular}{lc}
\hline Clinical diagnosis & $\begin{array}{r}\text { Number of subjects } \\
\text { (total } \mathrm{N}=30 \text { ) }\end{array}$ \\
\hline Psychiatric disorders & 9 \\
Neurological disorders & 7 \\
Hydrocephalus & 4 \\
Not confirmed CNS disease & 4 \\
Alcohol abuse & 1 \\
Dural fistula & 1 \\
Hypoacusis & 1 \\
Other tumors & 1 \\
Graves-Basedow disease & 1 \\
Stroke & 1 \\
\hline
\end{tabular}

Table 2

Demographic data and AD diagnostic parameters

\begin{tabular}{lccc}
\hline Variable & Non-AD $(\mathrm{N}=30)$ & $\mathrm{AD}(\mathrm{N}=30)$ & $p$-value \\
\hline Demographics & & & \\
$\quad$ Age (years) & $60 \pm 20$ & $68 \pm 8$ & $\mathrm{NS}$ \\
Male sex, $n(\%)$ & $13(43 \%)$ & $12(40 \%)$ & $\mathrm{NS}$ \\
Diagnostic parameters & $\mathrm{N}=6^{*}$ & $\mathrm{~N}=30$ & \\
$\mathrm{~A} \beta_{1-42}(\mathrm{ng} / \mathrm{L})$ & $1163 \pm 414$ & $537 \pm 148$ & 0.0002 \\
Tau (ng/L) & $138 \pm 40$ & $640 \pm 461$ & $<0.0001$ \\
Phospho-tau (ng/L) & $32 \pm 7$ & $78 \pm 29$ & $<0.0001$ \\
MMSE (points) & - & $21.43 \pm 4.14$ & $\mathrm{NA}$ \\
\hline
\end{tabular}

MMSE, Mini-Mental State Examination; NS, not significant; NA, not applicable. Data are expressed as Mean \pm S.D. Nonparametric two-sided Mann-Whitney test was applied to compare the two groups. *Non-AD subjects that experienced cognitive symptoms. 
AD patients showed the typical neurobiomarker pattern, with decreased concentration of CSF $\mathrm{A} \beta_{42}$, reflecting retention of the peptide in the brain parenchyma, and increased concentration of tau and phospho-tau protein, related to neurodegeneration (Table 2). In addition, all AD patients displayed MMSE score below 23 points. CSF PCSK9 levels and total apoE and apoE4 were measured by ELISA (R\&D Systems, Minneapolis, MN, USA and MBL, Nagoya, Japan, respectively). CSF total apoE and apoE4 levels measurement was performed on 27 out of $30 \mathrm{AD}$ patients, because 3 patients' aliquots were insufficient for all assays.

\section{Statistical analysis}

The sample size was calculated a priori by using The G*Power software [selecting $t$-test, difference between two independent means (two groups) and a priori power analysis]. Statistical analysis was performed with Graph Pad-Prism software version 5.0. Depending on variances analysis results, the two-tailed unpaired Student's $t$-test (for not statistically different variances) or two-sided nonparametric Mann-Whitney test (for statistically different variances) was applied to compare non-AD and $\mathrm{AD}$ patients' values. Relationships between parameters were performed by nonparametric correlation (Spearman $r$ reported). Significant differences were defined as $p<0.05$.

\section{RESULTS}

The analysis of CSF revealed that PCSK9 levels were significantly higher in $\mathrm{AD}$ patients than in nonAD controls $(+1.45$ fold; $p=0.0049$, Fig. 1A). In addition, $\mathrm{CSF}$ total apoE concentrations did not differ between the two groups (Fig. 1B); conversely, levels of the isoform apoE4 were higher in CSF of AD subjects compared to non-AD $(+3.34$ fold; $p=0.0068$, Fig. 1C).

We found a positive correlation between CSF total apoE and $\mathrm{A} \beta_{42}$ levels in the AD group $(r=0.4007$; $p=0.025$ ), as previously seen by others [15]. With respect to the relationship between PCSK9 and apoE in CSF, considering all samples together, PCSK9 did not significantly correlate with total apoE $(p=0.3656$, data not shown), but it positively correlated with apoE4 levels (Fig. 2A). Since apoE4 production is discrete and not continuous according to the null, heterozygous or homozygous genotype, the ratio apoE4/total apoE can be used to identify APOE $\varepsilon 4$ genotype [16]. Based on this concept we defined as APOE $\varepsilon 4$ carriers the individuals with apoE4/apoE ratio $>0(n=26)$. Interestingly we found that CSF PCSK9 levels were slightly and almost significantly higher in APOE $\varepsilon 4$ carriers among the non-AD subjects $(+1.83$ fold; $p=0.0775$; Fig. $2 \mathrm{~B})$; this difference reached statistical significance in the $\mathrm{AD}$ group $(+1.45$ fold; $p=0.0454$; Fig. 2 C) .

\section{DISCUSSION}

Although relative to a small sample size, our results show, for the first time, an increase of PCSK9 levels in CSF of AD patients. A potential involvement of PCSK9 in neurodegenerative conditions such as AD has been already suggested, but the existing reports are few and controversial.

For instance, a pro-apoptotic effect of PCSK9 in neurons has been proposed [17]. It was also recently shown that PCSK9 levels are elevated in serum of both mild cognitive impairment and $\mathrm{AD}$ patients [18]. Conversely, others reported a protective role of PCSK9 with respect to AD development, based on its degrading action on the $\beta$-site of amyloid- $\beta$ protein precursor (A $\beta P P$ ) cleaving enzyme (BACE1 ), involved in $A \beta_{42}$ production [19]. However, the latter effect was denied by the results of Liu and colleagues [20]. Finally, results of genetic studies did not find any association between PCSK9 polymorphism and risk of $\mathrm{AD}$ onset $[21,22]$. Our finding of increased CSF levels of PCSK9 in AD patients supports its involvement in $\mathrm{AD}$ pathogenesis.

It is hard at present to establish whether the increase of PCSK9 in the CSF is a consequence of $\mathrm{AD}$ or a causative factor. In this regard, it is relevant to consider that the PCSK9 expression in neuronal cells is stimulated in response to injury, as upon induction of apoptosis. In any case, an increased PCSK9 production is likely to be a pathogenic factor. First of all, high CSF PCSK9 levels might be associated to a reduced neuronal expression of the apoE-receptors in AD. This hypothesis is supported by the reported action of PCSK9 on neuronal apoE receptors such as LDLr, VLDLr, LRP1, and apoER2, implicated in brain lipid metabolism and AD pathogenesis [12]; consistently with this hypothesis, it has been recently shown that the plant-derived compound berberine is able to decrease PCSK9 neuronal expression and to upregulate the VLDLr and LRP [23]. Finally, an increased expression of the LDLr has been observed in brain of PCSK9 $9^{-/}$mice [24]. 

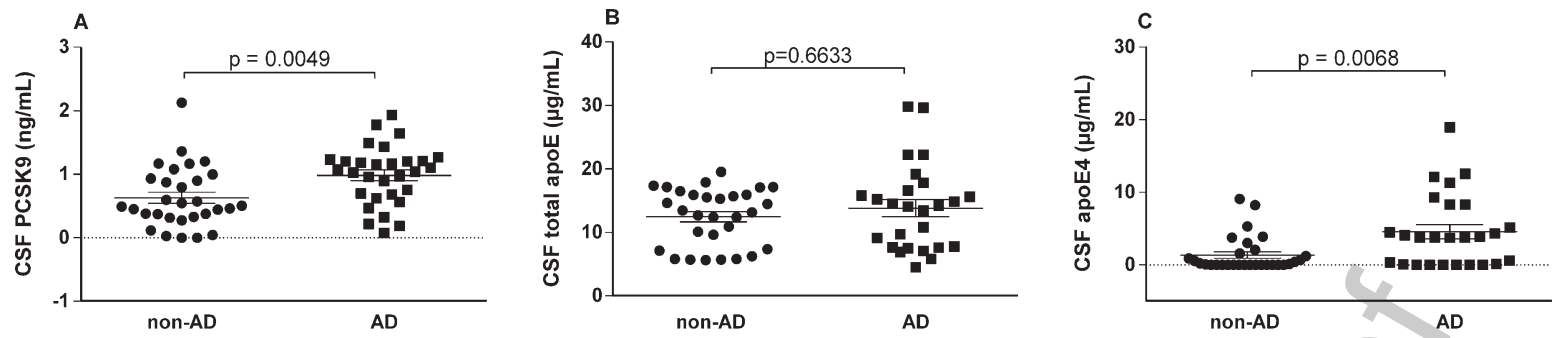

Fig. 1. PCSK9 (A), total apoE (B), and apoE4 (C) levels in CSF from non-AD $(n=30)$ and $\mathrm{AD}(n=30)$ patients. Each sample was run in duplicate. A, B) Two-tailed unpaired $t$-test was applied to compare the two groups. C) Nonparametric two-sided Mann-Whitney test was applied to compare the two groups. Mean \pm SEM is reported.
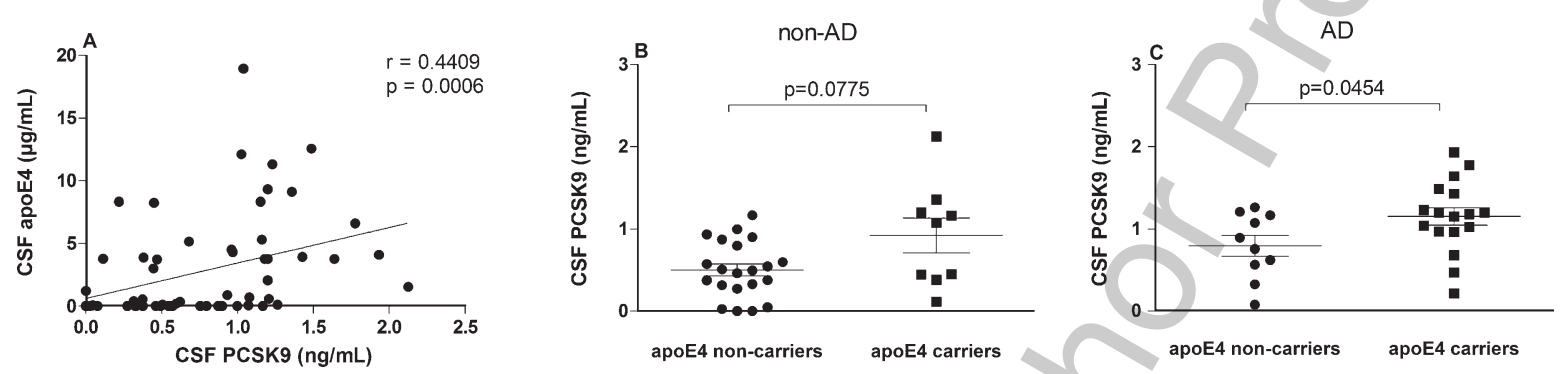

Fig. 2. Relationship between PCSK9 and apoE4 levels in CSF from non-AD and AD patients. A) Correlation between CSF PCSK9 and apoE4 levels in pooled non-AD and AD samples $(n=57)$. Analysis was performed by nonparametric correlation and Spearman $\mathrm{r}$ is reported. B) PCSK9 levels in non-carriers $(n=21)$ and carriers $(n=9)$ of APOE $\varepsilon 4$ among non-AD subjects. C) PCSK9 levels in non-carriers $(n=10)$ and carriers $(n=17)$ of APOE $\varepsilon 4$ among AD patients. Each sample was run in duplicate. Nonparametric two-sided Mann-Whitney test was applied in the case of non-AD subjects and two-tailed unpaired Student's $t$-test was used for AD patients. Mean \pm SEM is reported.

Reduced apoE receptor expression might in turn cause less cholesterol uptake, and possibly neuronal dysfunctions. In facts, while cholesterol synthesis in neurons and glial cells is high during embryogenesis, adult neurons progressively lose this capacity and almost exclusively rely on cholesterol produced from astrocytes to maintain neuronal development and synaptic plasticity [5]. In addition, beyond its potential involvement in altered apoE-mediated lipid trafficking, high PCSK9 levels might affect $A \beta$ deposition, one of the key events in AD pathogenesis. Indeed, the brain endothelial LRP1, which is degraded by PCSK9 [11], was recently shown to be involved in the $A \beta$ clearance from the CSF. LRP1 deletion results in reduced plasma $A \beta$, elevated brain $\mathrm{A} \beta$ deposition, and cognitive impairment in $\mathrm{AD}$ animal models [25].

Total apoE levels in CSF from our AD patients did not differ from those of controls, consistently with the results of a recent meta-analysis [26]. It may be speculated that, although increased apoE levels would be expected because of PSCK9-mediated receptor degradation, the apoE binding to $A \beta$ causes retention of apoE within the plaques, not allowing appreciating significant differences. The positive association between apoE levels and $A \beta_{42}$ seen in our present work and in others' [15] would be consistent with this hypothesis.

Conversely, apoE4 levels were significantly higher in the $\mathrm{AD}$ group, in accordance with the increased occurrence of apoE $\varepsilon 4$ genotype in this disease [27]. Interestingly, analyzing all CSF samples, we found a positive correlation between PCSK9 and apoE4 levels, clearly indicating a relationship between these two lipid-regulating molecules in the CNS. Such correlation was better clarified comparing CSF PCSK9 in APOE \&4 genotype carriers and non-carriers in both $\mathrm{AD}$ and non-AD subjects. Indeed, PCSK9 levels were higher in APOE \&4 carriers compared to noncarriers, reaching statistical significance in the $A D$ group. The mechanisms of the relationship between PCSK9 and apoE4 levels need to be explored, but a role of apoE4 in modulating PCSK9 production might be speculated; this hypothesis may be in line with the recently proposed role of apoE4 as transcriptional factor [28].

The limitations of this study are the small sample size and the characteristics of non-AD controls, the majority of which are patients with neurological or psychiatric diseases. This is because CSF collection 
is an invasive procedure, only practicable in the presence of strict clinical indication.

However, given the variety of conditions included in our study and because of the lack of a relationship between PCSK9 values and diagnosis in the control group, it is very unlikely that the significant difference in CSF PCSK9 levels between AD and non-AD patients may be affected by control group composition.

In conclusion, to the best of our knowledge, the results of this study suggest for the first time a possible link between PCSK9 levels, apoE4, and AD. Further studies are needed to fully elucidate the mechanisms relating PCSK9 modifications, brain cholesterol homeostasis, and $\mathrm{AD}$ development.

\section{ACKNOWLEDGMENTS}

The authors acknowledge Consortium TEFARCO Innova for research support.

Authors' disclosures available online (http://j-alz. com/manuscript-disclosures/16-0411r1).

\section{REFERENCES}

[1] Desikan RS, Schork AJ, Wang Y, Thompson WK, Dehghan A, Ridker PM, Chasman DI, McEvoy LK, Holland D, Chen CH, Karow DS, Brewer JB, Hess CP, Williams J, Sims R, O'Donovan MC, Choi SH, Bis JC, Ikram MA, Gudnason V, DeStefano AL, van der Lee SJ, Psaty BM, van Duijn CM, Launer L, Seshadri S, Pericak-Vance MA, Mayeux R, Haines JL, Farrer LA, Hardy J, Ulstein ID, Aarsland D, Fladby T, White LR, Sando SB, Rongve A, Witoelar A, Djurovic S, Hyman BT, Snaedal J, Steinberg S, Stefansson $\mathrm{H}$, Stefansson K, Schellenberg GD, Andreassen OA, Dale AM, Inflammation Working Group, International Genomics of Alzheimer's Disease Project (IGAP) and DemGene Investigators (2015) Polygenic overlap between C-reactive protein, plasma lipids, and Alzheimer disease. Circulation 131, 2061-2069.

[2] Lambert JC, Ibrahim-Verbaas CA, Harold D, Naj AC, Sims R, Bellenguez C, DeStafano AL, Bis JC, Beecham GW, Grenier-Boley B, Russo G, Thorton-Wells TA, Jones N, Smith AV, Chouraki V, Thomas C, Ikram MA, Zelenika D, Vardarajan BN, Kamatani Y, Lin CF, Gerrish A, Schmidt H, Kunkle B, Dunstan ML, Ruiz A, Bihoreau MT, Choi SH, Reitz C, Pasquier F, Cruchaga C, Craig D, Amin N, Berr C, Lopez OL, De Jager PL, Deramecourt V, Johnston JA, Evans D, Lovestone S, Letenneur L, Moron FJ, Rubinsztein DC, Eiriksdottir G, Sleegers K, Goate AM, Fievet N, Huentelman MW, Gill M, Brown K, Kamboh MI, Keller L, Barberger-Gateau P, McGuiness B, Larson EB, Green R, Myers AJ, Dufouil C, Todd S, Wallon D, Love S, Rogaeva E, Gallacher J, St George-Hyslop P, Clarimon J, Lleo A, Bayer A, Tsuang DW, Yu L, Tsolaki M, Bossu P, Spalletta G, Proitsi P, Collinge J, Sorbi S, SanchezGarcia F, Fox NC, Hardy J, Deniz Naranjo MC, Bosco P, Clarke R, Brayne C, Galimberti D, Mancuso M, Matthews F,
European Alzheimer's Disease Initiative (EADI), Genetic, Environmental Risk in Alzheimer's Disease, Alzheimer's Disease Genetic Consortium, Cohorts for Heart and Aging Research in Genomic Epidemiology, Moebus S, Mecocci P, Del Zompo M, Maier W, Hampel H, Pilotto A, Bullido M, Panza F, Caffarra P, Nacmias B, Gilbert JR, Mayhaus M, Lannefelt L, Hakonarson H, Pichler S, Carrasquillo MM, Ingelsson M, Beekly D, Alvarez V, Zou F, Valladares O, Younkin SG, Coto E, Hamilton-Nelson KL, Gu W, Razquin C, Pastor P, Mateo I, Owen MJ, Faber KM, Jonsson PV, Combarros O, O'Donovan MC, Cantwell LB, Soininen H, Blacker D, Mead S, Mosley TH Jr, Bennett DA, Harris TB, Fratiglioni L, Holmes C, de Bruijn RF, Passmore P, Montine TJ, Bettens K, Rotter JI, Brice A, Morgan K, Foroud TM, Kukull WA, Hannequin D, Powell JF, Nalls MA, Ritchie K, Lunetta KL, Kauwe JS, Boerwinkle E, Riemenschneider M, Boada M, Hiltuenen M, Martin ER, Schmidt R, Rujescu D, Wang LS, Dartigues JF, Mayeux R, Tzourio C, Hofman A, Nothen MM, Graff C, Psaty BM, Jones L, Haines JL, Holmans PA, Lathrop M, Pericak-Vance MA, Launer LJ, Farrer LA, van Duijn CM, Van Broeckhoven C, Moskvina V, Seshadri S, Williams J, Schellenberg GD, Amouyel P (2013) Meta-analysis of 74,046 individuals identifies 11 new susceptibility loci for Alzheimer's disease. Nat Genet 45, 1452-1458.

[3] Okoro EU, Zhao Y, Guo Z, Zhou L, Lin X, Yang H (2012) Apolipoprotein E4 is deficient in inducing macrophage ABCA1 expression and stimulating the Sp1 signaling pathway. PLoS One 7, e44430.

[4] Michikawa M, Fan QW, Isobe I, Yanagisawa K (2000) Apolipoprotein E exhibits isoform-specific promotion of lipid efflux from astrocytes and neurons in culture. $\mathrm{J} \mathrm{Neu}$ rochem 74, 1008-1016.

[5] Vitali C, Wellington CL, Calabresi L (2014) HDL and cholesterol handling in the brain. Cardiovasc Res 103, 405413.

[6] Ferri N, Ruscica M (2016) Proprotein convertase subtilisin/ kexin type 9 (PCSK9) and metabolic syndrome: Insights on insulin resistance, inflammation, and atherogenic dyslipidemia. Endocrine doi: 10.1007/s12020-016-0939-0

[7] Costet P, Krempf M, Cariou B (2008) PCSK9 and LDL cholesterol: Unravelling the target to design the bullet. Trends Biochem Sci 33, 426-434.

[8] Cariou B, Si-Tayeb K, Le May C (2015) Role of PCSK9 beyond liver involvement. Curr Opin Lipidol 26, 155-161.

[9] Seidah NG, Benjannet S, Wickham L, Marcinkiewicz J, Jasmin SB, Stifani S, Basak A, Prat A, Chretien M (2003) The secretory proprotein convertase neural apoptosisregulated convertase 1 (NARC-1): Liver regeneration and neuronal differentiation. Proc Natl Acad Sci U S A 100, 928-933.

[10] Chen YQ, Troutt JS, Konrad RJ (2014) PCSK9 is present in human cerebrospinal fluid and is maintained at remarkably constant concentrations throughout the course of the day. Lipids 49, 445-455.

[11] Canuel M, Sun X, Asselin MC, Paramithiotis E, Prat A, Seidah NG (2013) Proprotein convertase subtilisin/kexin type 9 (PCSK9) can mediate degradation of the low density lipoprotein receptor-related protein 1 (LRP-1). PLoS One 8, e64145.

[12] Poirier S, Mayer G, Benjannet S, Bergeron E, Marcinkiewicz J, Nassoury N, Mayer H, Nimpf J, Prat A, Seidah NG (2008) The proprotein convertase PCSK9 induces the degradation of low density lipoprotein 
receptor (LDLR) and its closest family members VLDLR and ApoER2. J Biol Chem 283, 2363-2372.

[13] Dubois B, Feldman HH, Jacova C, Dekosky ST, BarbergerGateau P, Cummings J, Delacourte A, Galasko D, Gauthier S, Jicha G, Meguro K, O’Brien J, Pasquier F, Robert P, Rossor M, Salloway S, Stern Y, Visser PJ, Scheltens P (2007) Research criteria for the diagnosis of Alzheimer's disease: Revising the NINCDS-ADRDA criteria. Lancet Neurol 6, 734-746.

[14] Dubois B, Feldman HH, Jacova C, Hampel H, Molinuevo JL, Blennow K, DeKosky ST, Gauthier S, Selkoe D, Bateman R, Cappa S, Crutch S, Engelborghs S, Frisoni GB, Fox NC, Galasko D, Habert MO, Jicha GA, Nordberg A, Pasquier F, Rabinovici G, Robert P, Rowe C, Salloway S, Sarazin M, Epelbaum S, de Souza LC, Vellas B, Visser PJ, Schneider L, Stern Y, Scheltens P, Cummings JL (2014) Advancing research diagnostic criteria for Alzheimer's disease: The IWG-2 criteria. Lancet Neurol 13, 614-629.

[15] Cruchaga C, Kauwe JS, Nowotny P, Bales K, Pickering EH, Mayo K, Bertelsen S, Hinrichs A, Alzheimer's Disease Neuroimaging I, Fagan AM, Holtzman DM, Morris JC, Goate AM (2012) Cerebrospinal fluid APOE levels: An endophenotype for genetic studies for Alzheimer's disease. Hum Mol Genet 21, 4558-4571.

[16] Fukumoto H, Ingelsson M, Garevik N, Wahlund LO, Nukina N, Yaguchi Y, Shibata M, Hyman BT, Rebeck GW, Irizarry MC (2003) APOE epsilon 3/epsilon 4 heterozygotes have an elevated proportion of apolipoprotein E4 in cerebrospinal fluid relative to plasma, independent of Alzheimer's disease diagnosis. Exp Neurol 183, 249-253.

[17] Bingham B, Shen R, Kotnis S, Lo CF, Ozenberger BA, Ghosh N, Kennedy JD, Jacobsen JS, Grenier JM, DiStefano PS, Chiang LW, Wood A (2006) Proapoptotic effects of NARC 1 (=PCSK9), the gene encoding a novel serine proteinase. Cytometry A 69, 1123-1131.

[18] Kang S, Jeong H, Baek JH, Lee SJ, Han SH, Cho HJ, Kim H, Hong HS, Kim YH, Yi EC, Seo SW, Na DL, Hwang D, Mook-Jung I (2016) PiB-PET imaging-based serum proteome profiles predict mild cognitive impairment and Alzheimer's disease. J Alzheimers Dis 53, 1563-1576.

[19] Jonas MC, Costantini C, Puglielli L (2008) PCSK9 is required for the disposal of non-acetylated intermediates of the nascent membrane protein BACE1. EMBO Rep 9, 916-922.
[20] Liu M, Wu G, Baysarowich J, Kavana M, Addona GH, Bierilo KK, Mudgett JS, Pavlovic G, Sitlani A, Renger JJ, Hubbard BK, Fisher TS, Zerbinatti CV (2010) PCSK9 is not involved in the degradation of LDL receptors and BACE1 in the adult mouse brain. J Lipid Res 51, 2611-2618.

[21] Reynolds CA, Hong MG, Eriksson UK, Blennow K, Wiklund F, Johansson B, Malmberg B, Berg S, Alexeyenko A, Gronberg H, Gatz M, Pedersen NL, Prince JA (2010) Analysis of lipid pathway genes indicates association of sequence variation near SREBF1/TOM1L2/ATPAF2 with dementia risk. Hum Mol Genet 19, 2068-2078.

[22] Shibata N, Ohnuma T, Higashi S, Higashi M, Usui C, Ohkubo T, Watanabe T, Kawashima R, Kitajima A, Ueki A, Nagao M, Arai H (2005) No genetic association between PCSK9 polymorphisms and Alzheimer's disease and plasma cholesterol level in Japanese patients. Psychiatr Genet 15, 239.

[23] Kysenius K, Huttunen HJ (2016) Stress-induced upregulation of VLDL receptor alters Wnt-signaling in neurons. Exp Cell Res 340, 238-247.

[24] Rousselet E, Marcinkiewicz J, Kriz J, Zhou A, Hatten ME, Prat A, Seidah NG (2011) PCSK9 reduces the protein levels of the LDL receptor in mouse brain during development and after ischemic stroke. J Lipid Res 52, 1383-1391.

[25] Storck SE, Meister S, Nahrath J, Meissner JN, Schubert N, Di Spiezio A, Baches S, Vandenbroucke RE, Bouter Y, Prikulis I, Korth C, Weggen S, Heimann A, Schwaninger M, Bayer TA, Pietrzik CU (2016) Endothelial LRP1 transports amyloid-beta 1-42 across the blood-brain barrier. J Clin Invest 126, 123-136.

[26] Talwar P, Sinha J, Grover S, Agarwal R, Kushwaha S, Srivastava MV, Kukreti R (2016) Meta-analysis of apolipoprotein E levels in the cerebrospinal fluid of patients with Alzheimer's disease. J Neurol Sci 360, 179-187.

[27] Michaelson DM (2014) APOE epsilon4: The most prevalent yet understudied risk factor for Alzheimer's disease. Alzheimers Dement 10, 861-868.

[28] Theendakara V, Peters-Libeu CA, Spilman P, Poksay KS, Bredesen DE, Rao RV (2016) Direct transcriptional effects of apolipoprotein E. J Neurosci 36, 685-700. 